\title{
Examing the Effect of a Learning-centered Reading Instruction on Iranian Students' Reading Comprehension: An Action Research
}

\author{
Seyyed Hossein Kashef ${ }^{1}$, Azizollah Viyani ${ }^{2}$, Neda Ghabool ${ }^{2} \&$ Ayoob Damavand ${ }^{2}$ \\ ${ }^{1}$ School of Languages, Literacies, and Translation, Universiti Sains Malaysia, Penang, Malaysia \\ ${ }^{2}$ School of Educational Studies, Universiti Sains Malaysia, Penang, Malaysia \\ Correspondence: Seyyed Hossein Kashef, School of Languages, Literacies, and Translation, Universiti Sains \\ Malaysia, 11800, Pulau Penang, Malaysia. Tel: 60-105-099-220. E-mail: mhkashef@gmail.com
}

Received: June 28, 2012 Accepted: July 9, 2012 Online Published: August 16, 2012

doi:10.5539/elt.v5n10p58 URL: http://dx.doi.org/10.5539/elt.v5n10p58

\begin{abstract}
This study intended to explore the the effect of a learning-centered reading instruction on improving undergraduate students' reading comprehension ability in university context of Iran. Based on a pedagogical framework driven from Hutchinson and Waters' learning-centered approach, some useful techniques were applied to develop a specific English reading instruction. The participants, within the age range of 18-22, included 50 students who were an intact experimental group. Following a pretest, treatment (15 weeks, 2 sessions per week), and a posttest, the obtained data was analyzed using t-test to examine the effect of the independent variable, namely, method of instruction. The results of the analysis showed that the teaching intervention had a significant effect on students' reading comprehension. The findings are discussed in relation to effective reading comprehension instruction through the use of necessary techniques in English teaching contexts.
\end{abstract}

Keywords: learning-centered, reading instruction, reading comprehension

\section{Introducation}

\subsection{Statement of the Problem}

In many EFL contexts of Asian countries, English is a required subject of students in all levels of their educational life. The main goal of instructing English in these contexts is to help students succeed in their examinations and enter higher levels of education (Huang, 2006). Although reading comprehension is an essential part of these exams, students usually do not receive any instruction on reading skills necessary to read some complicated texts in their educational life. Then, they enter university and study specific English related to their own fields of study and except English majors, they do not have to take English courses after the first year of their studies (Huang, 2006). The problem starts when the students have to struggle with some technical lengthy texts during their university life. This may be, partly due to the fact that instructors do not provide their students with different skills and strategies required to succeed in their reading comprehension goals. During such classes, as Huang (2006) mentions, some more proficient students will acquire some necessary reading skills by themselves, while other less proficient ones will lose their confidence and interest in the course and as a result they will refer to the translation versions of their texts in order to pass the exams. What is noteworthy is that in many EFL/ESL contexts, including Iranian context, English is commonly taught through the unfashionable Grammar-Translation Method (GTM) in teacher-centered classrooms which leads to poor reading comprehension (Hayati, 2008; Erfani et al. 2011; Atai and Nazari, 2011). Contrary to Fiorito's definition, what exists in the literature indicates that in GTM students have to learn language grammar and vocabulary so that they can be able to translate the readings and do the exercises (Chastain, 1988). Among the shortcomings of GTM, its lack of concern with cognitive principles (Chastain, 1988) leads to the inability of students to develop some necessary skills and strategies required in reading comprehension. This might be the worst pitfall that decreases its efficiency for English classes, which, according to Fuertes-Olivera and Gomez-Martinez (2004) leads to some passive learners who do not participate in class activities. Therefore, in this context, an effective method of instruction makes use of a number of appropriate features of a variety of teaching methods to develop learners' reading comprehension ability seems to contribute positively to learning outcomes. It seems that these classes will not train the students with satisfactory reading abilities. Therefore, it could be said that a reading 
course which concentrates on three main factors of meeting specific needs of the learners, making use of the underlying methodologies of the discipline it serves, as well as focusing on the appropriate skills necessary for this purpose will help the learners to succeed in their goals. In other words, a successful English reading course will be a course that takes into consideration three main factors of learners' needs, a suitable methodology, and the essential language skills needed by the learners to accomplish their objectives. This study builds on previous research studies emphasizing the role of instruction on study skills and techniques in English reading comprehension classes. However, it introduces Hutchinson and Waters' (1987) learning-centered approach as an innovative approach into English reading classroom in tertiary education context of Iran. In contrast to teacher-centered GTM classes, this approach takes into account learners' needs and priorities throughout the learning and teaching process and aims to consider learner at the center of learning.

\subsection{Significance of the Study}

Although a plethora of studies have intended to investigate the role of reading comprehension in second and foreign language academic contexts, it seems still necessary to conduct research attending to learners' required needs and skills in English reading comprehension, moving away from teacher-centered classes towards innovative classes in which teachers are not considered as the ultimate authorities in learning process. It could be claimed that English teaching practicioners need more attention to the role of learner in the classroom and their contribution to the learning process. This is particularly true in tertiary educational context of Iran where many classes are still conducted in teacher-centered GTM (Iranmehr, Erfani, \& Davari, 2011). Therefore, conducting a study on the possible influences of a learning-centered reading instruction to develop EFL students' reading comprehension seems warranted.

\subsection{Literature Review}

Several studies have been conducted with regard to English reading instruction in relation to the development of learners' different skills. In a recent study, Huang (2006) examined the ways that may motivate the students to engage in Englsih reading texts in an EFL context. He constructed a questionnaire including 18 statements describing various situations in which the students were motivated to read. Descriptive statistics showed that learners were most willing to read under three circumstances: when (1) teachers were available to answer the questions, (2) key points were highlighted clearly in textbooks, and (3) reading skills were taught (Huang, 2006). One can, therefore, infer from Huang's suggestion that teaching reading skills is one of the crucial factors that may motivate students to read efficiently. This, in turn, highlights the importance of teaching reading skills in an English reading course.

In this vein, Flowerdew and Peacock (2001) pointed out some necessary macro- and micro-skills of reading that are needed by English students. Making use of the learners' existing knowledge to understand new material and matching new knowledge with their schema are macro-skills; and recognizing logical relationships, definitions, generalizations, examples, explanations and predictions, and distinguishing fact from opinion are some crucial micro-skills. Similarly, Hauptman (2000) also noticed that learners with well-provided background knowledge but low language proficiency could get the main ideas of texts.

Similarly, Lee (2007) investigated the impact of reading strategy instruction on reading comprehension and strategy use of Korean university students. Seventy two students were chosen and divided into two distinct groups, one as an experimental and the other one as a control group. After implementing the intervention for 15 sessions, the results revealed that strategy instruction promoted students' study skills and enabled them to improve their reading comprehension.

In a very recent study, Hayati and Jalilifar (2010) carried out an experiment to investigate the effect of reading skills instruction delivering through TBLT on English reading comprehension of students. Forty-two students majoring in MBA were chosen and randomly assigned to two groups as participants. The experimental group was taught four reading skills namely, scanning, skimming, contextual clues, and critical reading through task-based language teaching, while the control group received the common translation instruction. Having taken a final examination, the participants reading micro-skills were tested. Independent samples t-test was utilized to find possible differences between the two groups. The results revealed that students in the experimental group having been instructed on reading skills via TBLT outperformed their counterparts in the control group showing a better academic performance and effective reading comprehension.

Iranmehr, Erfani, and Davari (2011) conducted a study to see the impact of Task-Based Language Teaching (TBLT) as a method which entails the use of language focusing on the consequence of the activity rather than on the language applied to achieve that consequence asserting that this method can provide good learning conditions for the students learning English. They criticized the current inappropriate teaching methods dominant in Iranian 
context and attempted to perform a research to examine the possibility of integrating TBLT as an alternative to the rather ineffective, but commonly applied method known as Grammar Translation Method (GTM) on English reading comprehension of Iranian students of chemistry at two Iranian universities. Two homogeneous groups as experimental and control at each university acted as the subjects of their study. The subjects in the control groups had to read the texts, translate them into Persian, and answer some traditional forms of reading comprehension questions, whereas their peers in the experimental groups studied the same texts but received a kind of task-based instruction together with exercises provided within Willis' TBLT framework. After a pretest and implementation of the treatment, a post test was given to the students. Finally, the researchers compared the students' performances to see the probable effectiveness of TBLT through t-test. The results indicated the significant privilege of teaching tasks as an innovative approach in English instruction context.

\subsection{Theoretical Framework}

The type of instruction implemented in the class was driven from the learning-centered approach of Hutchinson and Waters' (1987). An explanation of the principles of this approach seems warented here.

As the first principle, the developmental process of second language learning highlighting the importance of learners' background knowledge and the role of teachers in using it is mentioned. In other words, it is explained that learning happens only when learners utilize their existing knowledge to comprehend the new information. The second feature describes the active process of language learning. It represents that not only learners need to have the necessary knowledge, but also to participate actively in the process of learning through using that knowledge both as a psycho-motor activity and as a mental and cognitive process. Third, language learning is a decision-making process. While traditionally the teacher was supposed to make all the decisions in the classroom, the developing process of learning and using a network of knowledge depends on learner decisions. Next, language learning is not only having linguistic knowledge meaning that the most crucial problem of second language learning is the mismatch between learners' cognitive capacities and linguistic knowledge. It happens because second language learner is already mature cognitively; however, he or she is linguistically a child in the second language. This may be a common problem in English for Specific Purposes classes where students have specialist knowledge of their disciplines, but lack appropriate language proficiency and knowledge. Fifth, language learning is not the first experience of the learners with language. All second language learners have already a good command in their native language, thus, their mother tongue knowledge should be applied in second language learning to help them progress better. The outstanding role of emotions is highlighted as the sixth principle in second language learning. It is noted that teachers should attempt to develop positive emotions in the classroom and avoid negative emotions as much as possible for instance: applying pair work and group work; giving students time to think; emphasizing more on process rather than product; respecting attitude the same as aptitude and ability; considering interest, fun, and variety in methodology. The seventh principle signifies the incidental nature of language learning explaining that working on a language problem does not necessarily result in language learning. It can happen incidentally while thinking to something else. However, the point is that the language problems should urge the learners to utilize language and then to organize the language into the network of knowledge in their minds. Finally, it is highlighted that language learning is an unsystematic process. Although we learn through arranging information in a systematic manner, learning only takes place based on an internally-created system and the external system may pave the way, but does not guarantee learning.

\subsection{Research Hypothesis}

The focus of the present study is on the role of a learning-centered reading instruction in students' English reading comprehension in Iranian tertiary education context. Therefore, the following hypothesis was formulated:

Learning-centered reading instruction improves Iranian students' reading comprehension.

\section{Method}

Actually, this study is in an action research format conducted by a teacher during the instruction period to examine if the new intervention has any significant effect on improving students' reading comprehension. Action research is a kind of survey carried out by instructors which is more directed to teacher and learner improvement than it is to theory building, though it can be applied for theory building, as well (Mackey and Gass, 2005).

\subsection{Subjects}

The initial sample of this study consisted of 70 freshmen management students of Urmia University which formed an intact classs. By means of a three part questionnaire and a pretest, 50 homogeneous subjects were 
chosen in terms of their age range, reading comprehension ability, and motivational features for the purpose of this study. They consisted of 24 males and 26 females. The selected subjects were at the same level in terms of reading comprehension ability according to their obtained scores in the pretest. To make sure the equivalence and comparability of the pairs, extreme scores were discarded from the sample.

\subsection{Instruments}

For data collection purposes, the following instruments were used:

1. A questionnaire: The questionnaire was used to select a homogeneous group of students and also to control some intervening variables like motivation and age. It included some questions about the subjects' demographic information, English language experience, and motivation. The first part of the questionnaire elicited some main information about subjects including age range, and gender. In fact, to control the moderating effect of age, the subjects within the age range of 18 to 22 were selected for the purpose of this study. The second section elicited data on subjects' assessment of their English as well as their exposure to it. Data from this section lead to the exclusion of subjects who reported longer exposures to EFL or having stayed in English speaking countries for more than one year. Another section of the questionnaire examined learners' motivation towards English language learning. In order to have homogeneous groups in terms of motivation and to eliminate the mediating role of this important factor as much as possible, a modified version of Gardener's (1985) motivation questionnaire was used. This section contained 11 statements indicating integrative and instrumental motivation for English learning. It was assessed via a serious of Likert-format items that had five scales, including strongly agree, agree, neutral, disagree, and strongly disagree. Participants who were identified as not motivated integratively or instrumentally were excluded from the study.

2. General and Technical Reading Tests: Two standard and reliable tests of English reading comprehension, one as a pretest and the other one as a posttest were adopted. Both tests were divided into 2 parts, namely, general and specific English.

The general English section included 3 reading passage followed by 5 multiple-choice items. The specific section contained 2 reading passages (relevant to management students), each followed by 5 multiple-choice items. Both tests were piloted on 35 students and their reliability was calculated using the KR-21 formula. The reliability of the tests was within an acceptable range (pretest: 0.71 and posttest: 0.75 ).

\subsection{Procedures}

The study was conducted at Management Faculty of Urmia University. The participants formed a reading class that was held two sessions (approximately 90 minutes) a week. The class was an intact group taught by the researcher himself through learning-centered method. All the data was collected during 4 months. In the beginning, the questionnaire along with the pretest was administered to the learners in order to establish the initial ability of subjects and commence treatment. Then, after choosing homogeneous students (in terms of age range, language proficiency, and motivation), the experiment was started.

As already mentioned, the purpose of the study was to examine how a learning-centered method of reading instruction which teaches reading micro-skills can improve reading comprehension ability of students. Therefore, a group of study skills including a number of micro-skills, namely, skimming, scanning, identifying the purpose, and summarizing were introduced and taught as a pedagogical framework to the students.

\section{Results}

In order to analyze the obtained data, t-test was used to measure the possible effect of the method on the development of the student's reading comprehension ability.

As stated before, a reading comprehension test was administered as a pretest to examine the initial status of students and choose homogeneous subjects before starting the treatment. Based on the obtained results 50 students were chosen to begin with.

Then, data from the posttest was analyzed to see the effect of treatment. To test the proposed assumption, the author used paired t-test with the intact group taking method of instruction as independent variable and reading comprehension as the dependent one. The results of t-test revealed that the teaching intervention had a significant effect $(\mathrm{T}=-7.75, \mathrm{P} \leq .05)$ on students reading comprehension (Table 1$)$. This means that the instruction was quite successful in improving students' reading comprehension.

As the comparison of the means within the group (Table 2) shows, there is a remarkable difference between pretest $(M=62.42)$ and posttest $(M=69.96)$. Table 2 shows the descriptive statistics means and standard deviation across the pairs as far as reading comprehension ability is concerned. Figure 2 represents the 
interaction of pairs. It shows that the means of the intact group for pretest and posttest are clearly different. In other words, students'initial reading comprehension improved as a result of instruction.

Table 1. The results of t-test for reading comprehension

\begin{tabular}{lllll}
\hline Pairs & Mean & df & T & Sig. \\
\hline Pretest-Posttest & -7.54 & 49 & -7.75 & .000 \\
\hline $\mathrm{P} \leq .05$ & & & &
\end{tabular}

Table 2. Descriptive Statistics for the Posttest Scores

\begin{tabular}{llll}
\hline Pair & Mean & SD & N \\
\hline Pretest & 62.42 & 9.49 & 50 \\
\hline Posttest & 69.96 & 9.29 & 50 \\
\hline
\end{tabular}

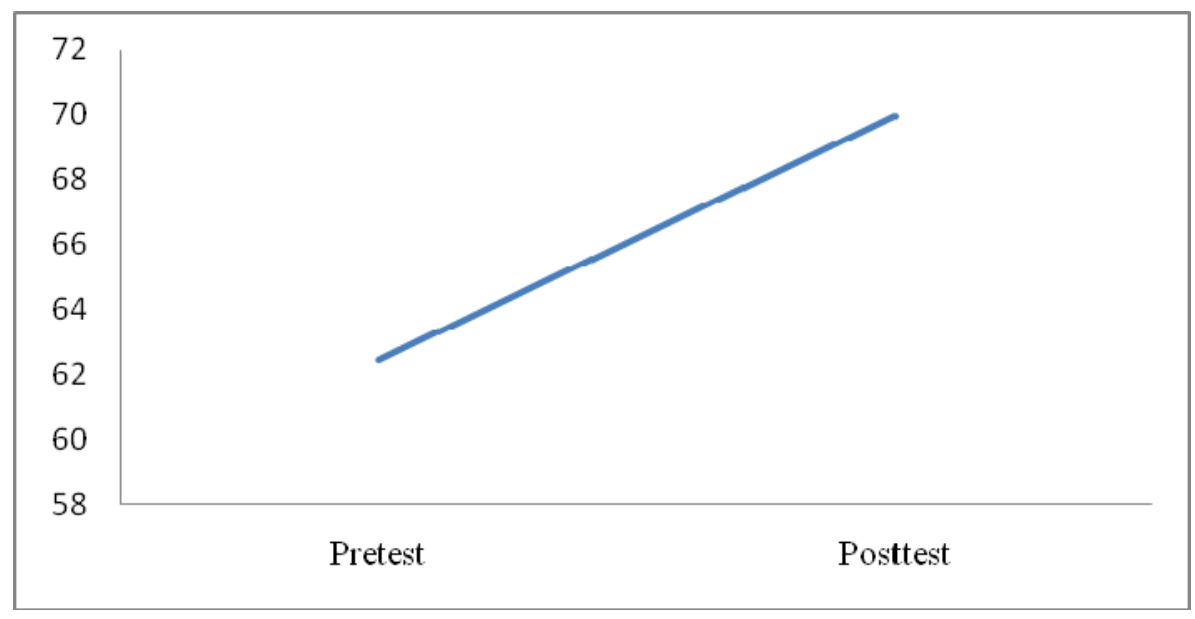

Figure 1. Means of Reading Comprehension Scores across Pairs

\section{Discussion and Conclusion}

According to Alderson (2000), L2 reading is a complicated, dynamic, and multi-dimensional process. The main reason might be due to its interactions among the reader's interlanguage competence (e.g. incomplete linguistic, strategic, discourse competence), personal characteristics (e.g. learning style, gender, motivation), and external contexts (topics, text characteristics, time constraints). Several studies have been carried out to understand the nature of L2 reading by focusing on reader factors and contextual factors (e.g. see Alderson, 2000). However, this study only intended to focus on pedagogical aspect controlling some personal and external variables such as age, motivation, time, and topic as proposed by Alderson (2000). It confirmed several researches (e.g. Huang, 2006; Flowerdew and Peacock, 2001: Lee, 2007; Hayati \& Jalilifar, 2010) proposing positive effects of direct and indirect reading instruction and strategies training on improving reading comprehension ability of students.

The findings emphasize the efficacy of training university EFL students in a variety of reading strategies and skills to empower them with the flexibility required to operate under different constraints in dealing with different types of reading texts (Carrell, 1996, 1998).

The present study adds to the previous body of research carried out on the role of innovative reading instruction in academic contexts. It encourages the implementation of a learning-centered approach towards reading comprehension as opposed to teacher-centered GTM classes. It approves the implementation of all crucial principles of Hutchinson and Waters' learning-centered approach which encourage the consideration of learner and his or her preferences and needs along the leaning process. 
As a result, this study supports the fact that teachers may have to devote sometime to be sure that their students correctly understand and accept the daily routines of a learning-centered methodology. The current study highlights the crucial effect of a reading instruction, focusing on micro-skills, on developing subjects' reading comprehension ability; however, the findings call attention to some issues to be considered in further research. This study, in an action research format, mainly focused on an intact group and one method of instruction and its effects on developing reading comprehension ability of undergraduate management students; further research might investigate the possible effects some other methods of instruction might have on students with different levels of motivation and in different fields of study.

\section{References}

Alderson, J. C. (2000). Assessing reading. Cambridge: Cambridge University Press. http://dx.doi.org/10.1017/CBO9780511732935

Atai, M. R., \& Nazari, O. (2011). Exploring Reading Comprehension Needs of Iranian EAP Students of Health Information Management (Him): A Triangulated Approach. System, 39(1), 30-43. http://dx.doi.org/10.1016/j.system.2011.01.015

Carrell, P. L. (1996). L2 reading strategy training: what is the role of metacognition? Paper presented at the 30th TESOL Annual Convention. Chicago, IL, 26-30 March.

Carrell, P. L. (1998). Can reading strategies be successfully taught? The Language Teacher (online), 22(3), 55 paragraphs. Retrieved from http://langue.hyper.chubu.ac.jp./jalt/pub/ttt/98/mar/carrell.html

Chastain, K. (1988). Developing second language skills, theory and practice. Harcourt Brace Jovanovich, Inc.

Erfani, S. M., Iranmehr, A., \& Davari, H. (2011). Deepening ESP reading comprehension through visualization. Journal of Language Teaching and Research, 2(1), 270-273. http://dx.doi.org/10.4304/jltr.2.1.270-273

Flowerdew, J., \& Peacock, M. (2001). Research Perspectives on English for Academic Purposes. Cambridge University Press, Cambridge.

Fuertes-Olivera, P. A., \& Gomez-Martinez, S. (2004). Empirical assessment of some learning factors affecting Spanish students of business English. Journal of English for Specific Purposes, 23(2), 163-180. http://dx.doi.org/10.1016/S0889-4906(02)00044-3

Gardner, R. C. (1985). Social psychology and second language learning. Edward Arnold.

Hauptman, P. C. (2000). Some hypotheses on the nature of difficulty and ease in second language reading: an application of schema theory. Foreign Language Annals, 33(6), 622-631. http://dx.doi.org/10.1111/j.1944-9720.2000.tb00931.x

Hayati, A. M. (2008). Teaching English for Special Purposes in Iran: Problems and suggestions. Arts and Humanities in Higher Education, 7, 149-165. http://dx.doi.org/10.1177/1474022208088645

Huang, S. C. (2006). Reading English for academic purposes -What situational factors may motivate learners to read? System, 34(3), 371-383. http://dx.doi.org/10.1016/j.system.2006.04.006

Hutchinson, T., \& Waters, A. (1987). English for Specific Purposes. Cambridge: Cambridge University Press. http://dx.doi.org/10.1017/CBO9780511733031

Iranmehr, A., Erfani, S. M., \& Davari, H. (2011). Integrating Task-based Instruction as an Alternative Approach in Teaching Reading Comprehension in English for Special Purposes: An Action Research. Theory and Practice in Language Studies, 1(2), 142-148. http://dx.doi.org/10.4304/tpls.1.2.142-148

Mackey, A., \& Gass, S. M. (2005). Second language research: methodology and design. Lawrence Erlbaum Associates, Inc., Publishers. 